Training

\section{Training in academic cardiology: prospects for a better future}

\section{P Weissberg, H Watkins, D Crossman, P Poole-Wilson}

$\mathrm{T}$ he current dearth of talented young doctors seeking to pursue a career in academic cardiology has resulted in a paucity of applicants for clinician scientist awards and failure to identify suitable candidates from within UK cardiology for vacant chairs. Such problems were anticipated long ago $^{1}$ and were re-emphasised at the start of "Calmanisation" of clinical training. ${ }^{2-4}$ It is not simply that young doctors are no longer interested in research, as there is no shortage of applications for junior research fellowships, although this figure is undoubtedly inflated by the large number of junior doctors seeking research as a means of gaining a national training number (NTN). So why do we fail to retain young doctors in academic cardiology? Early experience of the Wellcome Trust's Cardiovascular Research Initiatives in Oxford and Edinburgh has identified clinical training in cardiology as the major obstacle to successful achievement of one of the trust's stated aims: "to develop research training and career development of clinical scientists interested in cardiovascular research". The quest to ensure minimum standards of competency in all aspects of cardiological practice is resulting in uniformity at the expense of diversity and individuality to the inevitable detriment of academic cardiology.

The Savill report, The Tenure Track Clinician Scientist: a new career pathway to promote recruitment into academic medicine, recently published by the Academy of Medical Sciences, ${ }^{5}$ identified the following three key "generic" disincentives against an academic career: (1) lack of a clear career structure; (2) insufficient flexibility of clinical and research training opportunities for specialist registrars; and (3) prolonged insecurity While these disincentives apply to all disciplines, they are particularly important in "craft" specialties such as cardiology with its longer, procedure orientated, training programme. Also, compared with their National Health Service (NHS) peers, academics may have limited income from private practice, may receive no contribution towards relocation costs, may receive reduced intensity payments, and may be disadvantaged in the competition for discretionary awards.

Unless something is done to make the academic option more attractive than it currently is, young doctors will continue to vote with their feet and academic cardiology will cease to exist.

\section{ACADEMIC EXPECTATIONS}

Largely through pressures related to the research assessment exercise, today's academics are expected to produce internationally competitive research and secure MRC (Medical Research Council) or AMRC (Association of Medical Research Charities) research funding, preferably including their own salary, by way of a personal research fellowship or chair. This can only be achieved after a rigorous and extensive period of doctoral and postdoctoral research training, often in laboratory based science, that is not easily reconciled with the current clinical training requirements in cardiology. The perceived inflexibility of the cardiology training programme, coupled with the current difficulty in gaining an NTN without extensive cardiology experience at SHO (senior house officer) or LAT (locum appointment for training) level, are turning enthusiastic potential cardiovascular researchers away from the specialty and towards other academic disciplines with more flexible clinical training programmes.

\section{TRAINING FOR ACADEMIC CARDIOLOGY}

The Savill model proposes a two phase training programme following award of an NTN that can be adapted to provide promising young doctors with an attractive and secure career pathway in academic cardiology (fig 1).

Phase 1 comprises a period of "core" cardiology training involving three years full time clinical training, which would be common to all cardiology trainees, coupled with a separate period of research training leading to a higher degree. Ideally, a trainee would undertake two years full time clinical training during which an MRC or equivalent training fellowship is obtained. He or she would then undertake three years of full time research before returning to clinical training for a further year while the $\mathrm{PhD}$ (or, less likely, the MD) is conferred and publications come to fruition. During this year the trainee would make a decision on career options and, if committed and suited to academic medicine, would apply to enter phase 2 of the training programme. The components of phase 1 could be flexibly arranged to allow different permutations of clinical and research training to suite the trainee and the local centre. By the end of phase 1 all trainees will have achieved all the core training requirements in the revised cardiology curriculum in addition to a higher research degree.

Entry into phase 2, or academic training, would be dependent on securing a competitive clinician scientist award, and would confirm the trainee's commitment to academic medicine. Successful applicants for these posts will receive an NATN (national academic training number) and relinquish their NTN which would then be recycled. The Department of Health has committed funding for eight such national awards (across all specialties) per year over the next five years and has already called for applications for the first round. It is anticipated that a further 50 or so NATNs will be linked to clinician scientist awards from major research funders such as the MRC, BHF (British Heart Foundation) or Wellcome Trust each year. A case can also be made for linking NATNs with HEFC (Higher Education Funding Council) funded clinical lectureships. Trainees failing to gain an appropriate award would continue with conventional cardiology training.

On applying for a clinician scientist award an appropriate personalised clinical training programme would be agreed prospectively with the local training committee, the postgraduate dean, the STA, and the funding body. The overriding principals for assessing further training needs must be that all of the training (clinical and research) in phase 2 should be taken into account and that clinical training should be tailored towards the likely future clinical needs of the academic. This may or may not encompass training in invasive techniques, and assessment should be based on competency rather than on numbers of procedures or time elapsed. The training programme acknowledges that future academics may desire a more narrowly

Abbreviations: AMRC, Association of Medical Research Charities; BHF, British Heart Foundation; HEFC, Higher Education Funding Council; LAT, locum appointment for training MRC, Medical Research Council; NATN, national academic training number; NHS National Health Service; NTN, national training number; $\mathrm{SHO}$, senior house officer. 


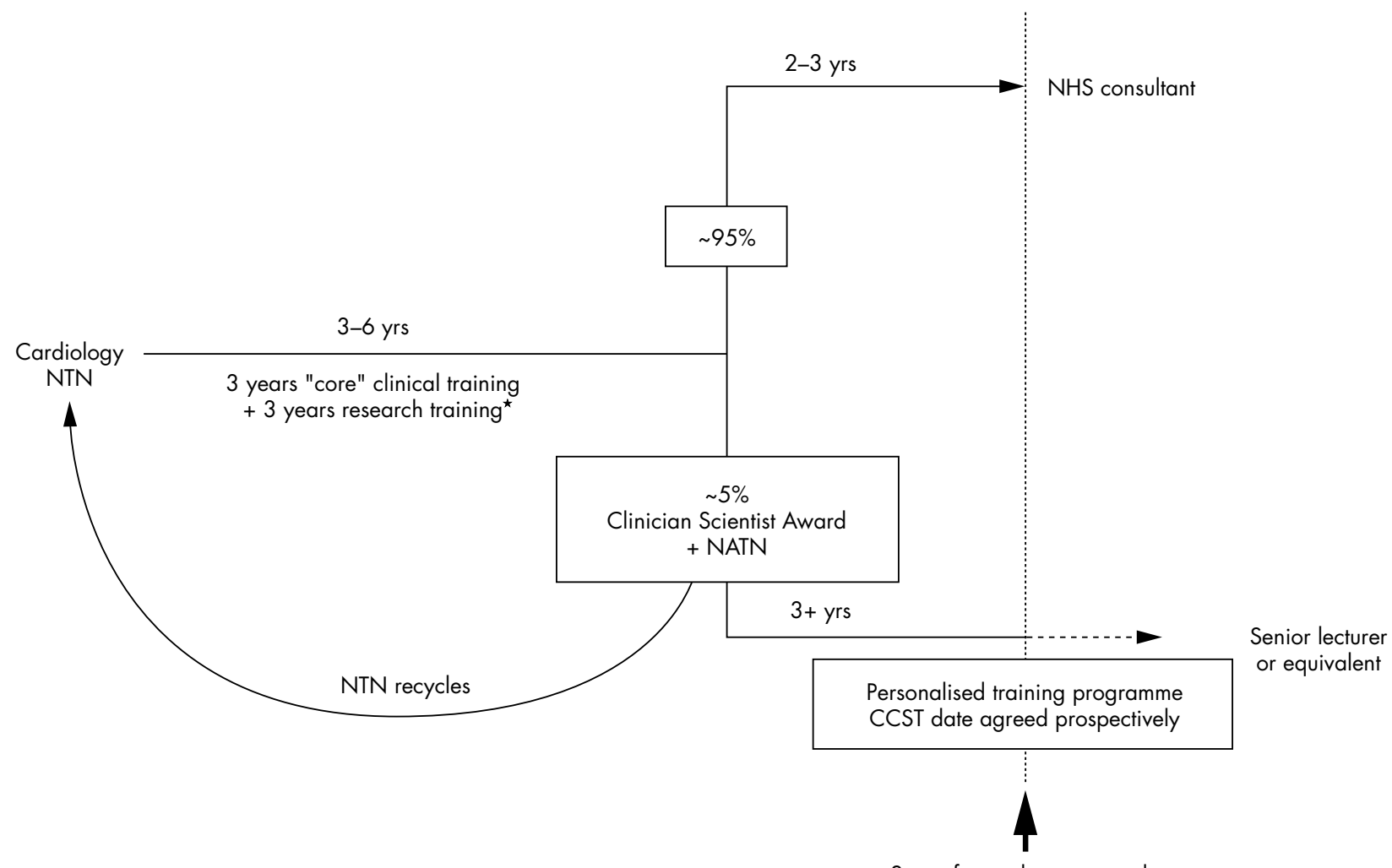

Start of consultant pay scale

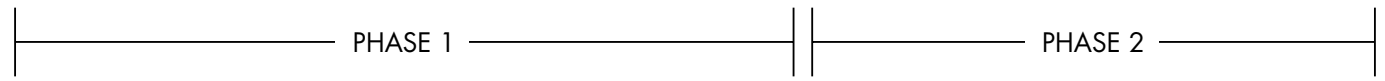

^Essential for potential academics, optional for non-academic trainees

Figure 1 Proposed academic training programme, with phase 1 being common to all cardiology trainees and phase 2 accessible only to those who have gained a clinician scientist award.

defined clinical role than in the past and that the process of clinical governance will ensure that consultants, academic or otherwise, do not undertake inappropriate clinical activities. It is not a mechanism for avoiding clinical training. The duration of phase 2 would vary according to the clinical and research training requirements of the individual, but would usually be between three and five years.

It is anticipated that the academic pathway would apply to only a small minority of trainees, estimated at less than $5 \%$ of the total. Commitment to, and success in, gaining an externally assessed fellowship would select those candidates who have a serious intent on an academic career (and the aptitude to succeed) and who are unlikely, therefore, to "default" thereafter to an NHS appointment. Although the academy's document also proposes that clinician scientist awards should be linked to "tenure track" senior appointments, this is likely to prove difficult to deliver, particularly in centres of research excellence where it would be impractical to offer tenured positions to all research trainees. Given the current dearth of suitable applicants for senior academic positions in cardiology, it is almost inconceivable that a trainee who has gained an NATN by this process will not be an attractive candidate for a senior lecturer or equivalent position in most UK universities.

MAKING THE PROGRAMME WORK The proposed programme offers an attractive career pathway for academically talented individuals. However, it is unlikely to reverse the current trend away from academic cardiology unless a number of longstanding anomalies are also corrected.

It is crucial that academic trainees should maintain parity of pay and status with their NHS peers. ${ }^{4}$ A research career is not a "soft option" where quality of life compensates for reduced income.

It is a "sine qua non" that the academic training programme can only succeed if academically gifted doctors are admitted to cardiology training in the first place. The limited number of available NTNs, coupled with the heavy clinical demands in cardiology departments, have biased appointments committees away from academically promising young SHOs towards short listing often less gifted individuals who have "proven themselves" in LAT posts.

Worse still is the increasing expectation (and in some instances requirement) that candidates for an NTN must have completed a period of research before applying. This distorts the motivation for research, usually at the expense of quality, and abuses scarce research resources. Research is best undertaken once the trainee has had some experience of the field and has had an opportunity to identify the type and direction of his or her research aspirations. It is crucial that once initiated, research momentum can be maintained without long periods of interruption for clinical training.

IMPLICATIONS FOR THE FUTURE

Adoption of these proposals has important implications for cardiologists, universities, funding bodies, statutory authorities, trainers, and trainees.

Cardiologists must acknowledge the current crisis and take ownership of, and responsibility for, the future of cardiovascular science in the UK by encouraging timely appointment of academically 
gifted individuals to their rotations. Service provision will not be jeopardised by granting a scarce NTN to an aspiring academic, since entry into phase 2 would allow recycling of the NTN.

Additional funding for NATNs must be provided via clinician scientist awards. This should not prove difficult since the numbers involved will be small and many research funding bodies already have appropriate fellowship schemes.

The authorities responsible for setting standards and curricula must ensure that they give appropriate consideration to the needs of academics and that they are conversant with current academic trends and requirements. Training committees should pay as much attention to a trainee's academic development as they currently do to their procedural competence.

In return for a personalised training programme, potential academics will have to make an earlier commitment to an academic career than in the past and accept that default into an NHS post is an unlikely option.

\section{CONCLUSION}

At a time when cardiology is being driven ever harder to meet NHS needs, there is a serious risk that UK cardiology will be relegated to a purely technical discipline devoid of intellectual challenge. Cardiology fortunately attracts some of the brightest medical graduates who, at least in the early stages of their career, are keen to undertake research. It is in our best interests to ensure that such individuals are given every opportunity to fulfil their academic potential within the specialty. Through cooperation between the Cardiology SAC, the STA, universities and research funding bodies, in particular the BHF, there is an opportunity to reverse the current exodus of talent and re-establish UK cardiology at the forefront of international cardiovascular research.

Heart 2002;87: 198-200

\section{Authors' affiliations}

P Weissberg, Division of Cardiovascular Medicine, Addenbrookes Hospital, Cambridge, UK
H Watkins, Department of Cardiovascular Medicine, University of Oxford, John Radcliffe Hospital, Oxford, UK

D Crossman, Cardiovascular Research Group, Clinical Sciences Centre, Northern General Hospital, Sheffield, UK

P Poole-Wilson, National Heart and Lung Institute, Imperial College, London, UK

P Weissberg, H Watkins and P Poole-Wilson hold BHF chairs.

Correspondence to: Professor Peter L Weissberg, Division of Cardiovascular Medicine, ACCl, Box 1 10, Addenbrooke's Hospital, Cambridge CB2 2QQ, UK plw@mole.bio.cam.ac.uk

\section{REFERENCES}

1 Oliver MF. Crisis in cardiovascular research in Britain. Br Heart J 1989;62:325-7.

2 Weissberg PL. Training for academic cardiovascular medicine. Heart 1996:75:118

3 de Bono D, Gershlick AH, Samani NJ, Garratt CJ. New training guidelines: what are the implications for cardiological research? Heart 1996;75: 1 18-20.

4 Weissberg PL. Clinical academic medicine. Academics should be rewarded appropriately [letter]. BM 2000;321:300-1.

5 Savill J. More in expectation than in hope: a new attitude to training in clinical academic medicine. BM 2000;320:630-3.

\section{STAMPS IN CARDIOLOGY}

\section{Conferences}

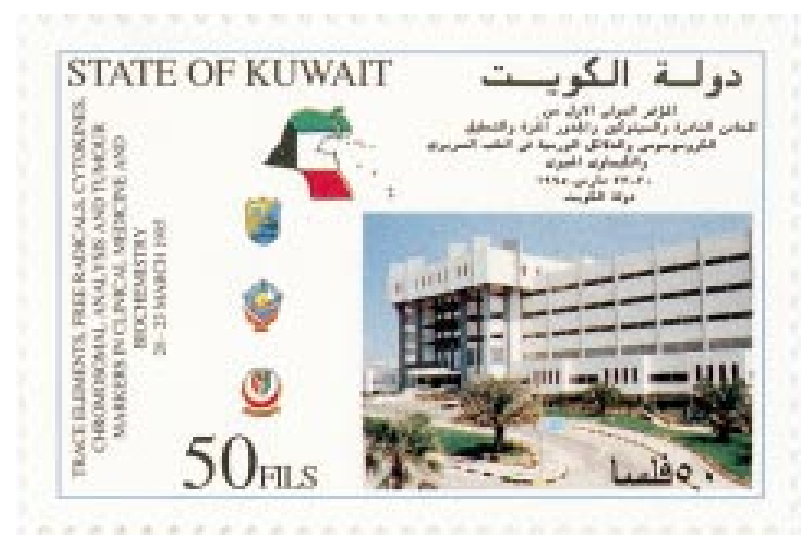

ree radical damage and the role of cytokines in the pathophysio- logy of various cardiac diseases is the subject of considerable current cardiovascular and medical research. The only stamp which has been released specifically relating to these compounds came from Kuwait in 1995. This was to mark the international medical conference on trace elements, free radicals, cytokines, chromosomal analysis, and tumour markers in clinical medicine and biochemistry held on 20-23 March 1995.

M K Davies A Hollman 